\title{
Direct-sun total ozone data from a spectroradiometer: methodology and comparison with satellite observations
}

\author{
M. Antón ${ }^{1}$, R. Román ${ }^{2}$, A. Valenzuela ${ }^{3,4}$, F. J. Olmo ${ }^{3,4}$, and L. Alados-Arboledas ${ }^{3,4}$ \\ ${ }^{1}$ Departamento de Física, Universidad de Extremadura, Badajoz, Spain \\ ${ }^{2}$ Departamento de Física Aplicada, Universidad de Valladolid, Valladolid, Spain \\ ${ }^{3}$ Centro Andaluz de Medioambiente (CEAMA), Universidad de Granada, Granada, Spain \\ ${ }^{4}$ Departamento de Física Aplicada, Universidad de Granada, Granada, Spain
}

Correspondence to: M. Antón (mananton@unex.es)

Received: 12 September 2012 - Published in Atmos. Meas. Tech. Discuss.: 5 November 2012

Revised: 25 February 2013 - Accepted: 28 February 2013 - Published: 12 March 2013

Abstract. A methodology to obtain the total ozone column (TOC) from the direct-sun spectral measurements of a Bentham spectroradiometer located at Granada (Spain) is presented in this paper. The method relies on the differential absorption technique using two pairs of direct irradiance at adjacent wavelengths between 305 and $340 \mathrm{~nm}$. The extraterrestrial constant was determined from the extrapolation to zero air mass of each wavelength pair (Langley plot method). We checked the strong influence of the cloud cover on the Bentham TOC measurements using simultaneous sky images taken with an all-sky camera. Thus, reliable TOC data are exclusively obtained during cloud-free conditions or partly cloudy conditions without the solar disk obstructed. In this work, the hourly TOC averages retrieved by the Bentham instrument with a standard deviation smaller than $3 \%(\sim 10$ Dobson Unit) are selected as high-quality TOC data. The analysis of the diurnal TOC variations during cloud-free days in late spring and summer showed different TOC values between the morning and afternoon periods. Thus, while the mornings exhibit an almost stable pattern, the afternoons display a monotonic TOC increase which could be partially related to photochemical processes in the lower troposphere associated with the formation of surface ozone. Finally, the Bentham TOC measurements were compared against the satellite data derived from three satellite instruments: OMI, GOME and SCIAMACHY. The mean absolute values of the relative differences between satellite and ground-based data were smaller than $3 \%$, highlighting the high reliability of the retrieval method proposed in this paper to derive TOC data.

\section{Introduction}

It is well known that ozone plays a very important role in atmospheric chemistry, since it absorbs the most energetic part of the solar ultraviolet (UV) radiation spectrum, protecting life on the Earth's surface from this detrimental radiation. Additionally, ozone is a greenhouse gas, so change in its column abundance may contribute to global climate change (Kiehl et al., 1999; Rex et al., 2004). The ozone layer depletion during the past two decades and the expected ozone recovery after the successful implementation of the Montreal Protocol have a great interest for human society (Zerefos et al., 2012). Therefore, it remains important to measure the magnitude of the ozone changes and monitor their long- and short-term trends over different regions (World Meteorological Organization (WMO), 2006). For that, the well-established, worldwide network of Brewer and Dobson spectrophotometers is a crucial tool (Komhyr, 1980; Basher, 1982; Kerr et al., 1984; WMO, 2008a). However, this ground-based network cannot provide the global data sets which are needed to characterize the Earth's atmosphere as a whole. Thus, remote sensing observations from satellite instruments play a key role in this task. To assess the quality of these remote sensing observations, the intercomparison of satellite products with reliable ground-based measurements is an essential activity (e.g., Fioletov et al., 2002; Balis et al., 2007; Antón et al., 2010a, 2011a, b). In addition, these accurate ground-based instruments are also required for forecasting tasks in several fields such as climate change, air 
pollution, and public information of the UV index (e.g., Long et al., 1996; Schmalwieser and Schauberger, 2000).

Although there are several methods to derive total ozone from the ground (e.g., direct moon, zenith sky irradiances, and look-up table using experimental and modeled global irradiances), WMO has established that the differential optical absorption technique applied to direct solar radiation at UV wavebands between 305 and $340 \mathrm{~nm}$ is the most accurate and the best-defined method for determining the total ozone column (TOC) (WMO, 2008b). The Brewer and Dobson spectrophotometers rely on this technique, and it is generally considered as the standard method for surface remote sensing of the TOC (Komhyr, 1980; Kerr et al., 1984; WMO, 2008a). In addition, TOC data using the same method have been derived from other ground-based instruments such as the M-83 and M-124 filter ozonemeters (Bojkov et al., 1994), the Total Ozone Portable Spectrometer (TOPS) (Flinn et al., 1996), the microprocessor-controlled version of TOPS (MICROTOPS) (Morys et al., 2001), the Ultraviolet Multifilter Rotating Shadowband Radiometer (UV-MFRSR) (Gao et al., 2001), and the Jobin Yvon spectroradiometer (Kiedron et al., 2007).

The Bentham DMc 150 instrument is a spectroradiometer designed for measuring the spectral irradiance scanning the range between $280-600 \mathrm{~nm}$. This instrument can record the direct spectral irradiance through a collimator tube mounted in a sun tracker. Thus, the Bentham direct solar measurements allow the determination of the TOC data by means of the differential absorption technique. However, to our knowledge, there are not any publications in the literature about the TOC retrieved using direct-sun measurements from Bentham spectroradiometers. Lenoble et al. (2004) derived TOC data from a Bentham instrument located at Briançon (France) using an estimated direct-sun irradiance from the difference between global and diffuse irradiances. Instead of the differential absorption technique, the retrieval method used in that work was based on the slope of the spectrum between 305 and $330 \mathrm{~nm}$, correlated with ozone cross sections. On the other hand, Brogniez et al. (2005) applied a TOC retrieval that fit radiative transfer model simulations with global spectral measurements recorded by two Bentham instruments at Sonnblick (Austria) and Briançon (France). A Bentham DMc 150 was also used by Lenoble et al. (2008) to retrieve the spectral aerosol optical depth in the UV range in the southern French Alps, estimating the direct irradiance from global and diffuse measurements.

In this framework, the main objective of this paper is to retrieve TOC data from direct-sun measurements recorded by a Bentham spectroradiometer located at Granada (Spain), using the differential absorption technique. Additionally, these TOC measurements are compared with satellite observations from three instruments: the Ozone Monitoring Instrument (OMI) on board AURA, the Global Ozone Monitoring Experiment (GOME) on board ERS-2 and the Scanning
Imaging Absorption spectroMeter for Atmospheric CartograpHY (SCIAMACHY) on board ENVISAT.

The paper is organized as follows. The ground-based measurements and satellite observations are described in Sect. 2. Section 3 introduces the methodology used to retrieve the TOC data from the Bentham spectroradiometer. Section 4 focuses on the determination of the extraterrestrial constant. Results and discussion are presented in Sect. 5. Finally, Sect. 6 summarizes the main conclusions of the work.

\section{Data}

\subsection{Ground-based measurements}

A Bentham double monochromator spectroradiometer (DMc150) has been installed since 2005 at the Andalusian Center for Environmental Studies (CEAMA), Granada, Spain $\left(37.2^{\circ} \mathrm{N}, 3.6^{\circ} \mathrm{W}, 680 \mathrm{~m}\right.$ above sea level), and it is operated by the Physics Atmospheric Group of the University of Granada. The full width at half maximum (FWHM) is $1.05 \mathrm{~nm}$, being determined by a laser light at $325 \mathrm{~nm}$, and the uncertainty in the wavelength is lower than $0.1 \mathrm{~nm}$. The total focal length is $300 \mathrm{~mm}$. A photomultiplier tube (R1527 Hamamatsu) is installed in the output of the monochromator to register the scattered UV light; this detector is provided with a blue filter to reject visible stray light. The input of the double monochromator is connected to two diffusers installed at the CEAMA rooftop by means of two optical fibers (LI-J1010). One diffuser is employed to measure global and diffuse irradiances which are not used in this work. The second diffuser takes direct irradiance measurements from a collimator tube with three optical diaphragms (field of view of $1.2^{\circ}$ ) which is mounted in a sun tracker (2AP model from Kipp and Zonen). The pointing accuracy of the sun tracker is better than $0.02^{\circ}$ due to a sun sensor, which guaranties that the collimator tube is always looking into the sun disk. The double monochromator and the detector are installed in a container in which temperature is stabilized at $25^{\circ} \mathrm{C}$ by a peltier cell air/air system. The whole formed by the double monochromator, the detector and the diffusers (with the optical fibers) is called in this work the Bentham spectroradiometer. This instrument is programed to take diurnal measurements of global, direct and diffuse UV spectral irradiance between $280 \mathrm{~nm}$ and $400 \mathrm{~nm}$ (each $0.5 \mathrm{~nm}$ ) every $15 \mathrm{~min}$ (Román et al., 2013). A full spectrum of direct irradiance is approximately taken in $4 \mathrm{~min}$ (one second per measured wavelength). The slit function was measured and is not triangular, but as a first approximation we consider it to be so because it makes easier calculations. In fact, the measured slit function and the triangular function are similar in $-1 \mathrm{~nm}$, $0.5 \mathrm{~nm}, 0 \mathrm{~nm}, 0.5 \mathrm{~nm}$ and $1 \mathrm{~nm}$, the points that we use in the measurements (every $0.5 \mathrm{~nm}$ ).

The Bentham spectroradiometer used in this study possesses an excellent maintenance record. In this sense, a 
calibration procedure is performed monthly using a mercury lamp (wavelength shift correction) and a pre-calibrated $120 \mathrm{~W}$ lamp (NIST standard), following the method of Sperling et al. (1996). The raw signal is first wavelength shift corrected and then converted into physical units $\left(\mathrm{W} \mathrm{m}^{-2} \mathrm{~nm}^{-1}\right)$, using the measurements of the calibrated lamp and the convolution of the spectra, assuming a triangular slit function of the spectroradiometer with a FWHM of $1.05 \mathrm{~nm}$ (Slaper et al., 1995). Bernhard and Seckmeyer (1999) quantified the different radiometric uncertainties in the spectral irradiance measurements of a similar UV spectroradiometer; combining these uncertainties without taking into account cosine error and leveling, our device presents in the direct irradiance measurements an expanded uncertainty ( $95 \%$ confidence) of $9.8 \%, 6.3 \%$ and $6.6 \%$ for 300,350 and $400 \mathrm{~nm}$, respectively, for solar zenith angle (SZA) equal to $30^{\circ}$. The uncertainties for $\mathrm{SZA}=60^{\circ}$ are similar, except for $300 \mathrm{~nm}$ when it rises up to $12.6 \%$. The signal-to-noise ratio at $300 \mathrm{~nm}$ is 0.026 and 0.01 at $350 \mathrm{~nm}$ for SZA equal to $30^{\circ}$; when SZA is $60^{\circ}$ this ratio rises to 0.04 at $300 \mathrm{~nm}$, and it is still 0.01 at $350 \mathrm{~nm}$ (Bernhard and Seckmeyer, 1999).

\subsection{Satellite observations}

The OMI instrument is a nadir-viewing wide-swath UVvisible hyperspectral spectrometer which was launched on board the NASA EOS-Aura satellite platform in July 2004 (Levelt et al., 2006). This satellite instrument measures the solar light backscattered to space by the Earth's atmosphere, and surface in the wavelength range from 270 to $500 \mathrm{~nm}$ with a spectral resolution of $0.45 \mathrm{~nm}$ in the ultraviolet and $0.63 \mathrm{~nm}$ in the visible. The instrument has a $2600-\mathrm{km}$-wide viewing swath such that it is capable of daily, global contiguous mapping of total ozone with an unprecedented high spatial resolution of $13 \times 24 \mathrm{~km}^{2}$ at nadir. The OMI retrieval algorithm used in this paper (called OMI-TOMS) works with measurements at four discrete 1 -nm-wide wavelength bands centered at $313,318,331$ and $360 \mathrm{~nm}$, and it applies an empirical correction to remove errors due mainly to aerosols and clouds (Bhartia and Wellemeyer, 2002).

The ESA GOME on board the second European sensing satellite (European Remote Sensing Satellite 2, ERS-2) has been recording global measurements of total ozone column since July 1995 (Burrows et al., 1999). The ground swath $(960 \mathrm{~km})$ is divided into three ground pixels of $320 \mathrm{~km}$ (across orbit) $\times 40 \mathrm{~km}$ (along orbit). The operational algorithm for the retrieval of total ozone column from this satellite instrument is the GOME Data Processor (GDP), which has undergone several years of progressive improvement since its first release in 1995 (Van Roozendael et al., 2006; Loyola et al., 2011). The GDP algorithm has two main steps to derive TOC data: the Differential Optical Absorption Spectroscopy (DOAS) least-squares fitting for the ozone slant column, followed by the computation of a suitable Air
Mass Factor (AMF) to make the conversion to the vertical column density.

The SCIAMACHY was launched in March 2002 aboard the European platform ENVISAT. This satellite instrument has a total swath width of $960 \mathrm{~km}$ with a typical spatial resolution in nadir of $60 \mathrm{~km}$ across track by $30 \mathrm{~km}$ along track (Bovensmann et al., 1999). The SCIAMACHY Ground Processor (SGP) version 5.0 is the current operational algorithm for the retrieval of total ozone column from this satellite instrument, which is based on the GDP. More details about this algorithm can also be found in the work of Lerot et al. (2009).

\section{Total ozone retrieval}

Attenuation of direct-sun irradiance through the atmosphere can be described by the Beer-Lambert law (e.g., Iqbal, 1983). This law assumes that the measured intensity of direct-sun spectral irradiance $I_{\lambda}$ at the Earth's surface can be approximated as

$\operatorname{Ln} I_{\lambda}=\operatorname{Ln} I_{0 \lambda}-\left[\alpha_{\lambda} \mu \Omega+\beta_{\lambda} \frac{p}{p_{0}} m+\delta_{\lambda} \sec \theta\right]$,

where

- $I_{0 \lambda}$ is the solar irradiance at the top of the atmosphere (extraterrestrial irradiance) at wavelength $\lambda$.

$-\alpha_{\lambda}$ is the ozone absorption coefficient at wavelength $\lambda$.

- $\mu$ is the relative optical air mass of the ozone layer (the ratio of the slant path of the beam through the ozone layer to the vertical path).

- $\Omega$ is the total ozone column in the atmosphere expressed in Dobson units $\left(1 \mathrm{DU}=10^{-3} \mathrm{~cm}\right.$ pure ozone at standard temperature and pressure).

- $\beta_{\lambda}$ is the Rayleigh molecular scattering coefficient of the air at wavelength $\lambda$.

- $p$ and $p_{0}$ are the station pressure and the mean sea level pressure at $1013.25 \mathrm{hPa}$, respectively.

- $m$ is the relative optical air mass of the whole atmosphere (the ratio of the slant path of the beam through the whole atmosphere to the vertical path).

$-\delta_{\lambda}$ is the aerosol scattering coefficient (optical depth) at wavelength $\lambda$.

- $\theta$ is the SZA, in degrees.

In general, TOC values are retrieved from the measurements of the direct solar irradiances at more than one wavelength by differential optical absorption techniques. In this study the double-pair wavelengths, $305.5 / 325.5 \mathrm{~nm}$ (A1/A2) and $317.5 / 340.0 \mathrm{~nm}$ (D1/D2), which approximately correspond 
to the A (305.5-325.4 nm) and the $\mathrm{D}(317.6-339.8 \mathrm{~nm})$ pairs for the Dobson instrument (WMO, 2003; Basher, 1982; Komhyr, 1980) have been chosen to obtain the TOC from the Bentham spectroradiometer. These two pairs of adjacent wavelengths with different ozone absorption coefficients are selected to minimize the effects of other atmospheric constituents, mainly aerosols, with the absorption by ozone being the major factor affecting the relative intensities of these double-wavelength pairs. Therefore, measurements of irradiances made at those four wavelengths are expressed by four equations of the form given in expression 1 with different values for $I_{0 \lambda}, \alpha_{\lambda}, \beta_{\lambda}$ and $\delta_{\lambda}$. These four equations may be linearly combined to obtain the total column ozone as (WMO, 2008b; Vanicek, 2006; Scarnato et al., 2009)

$\Omega=\frac{F_{0}-F-\left[\beta \cdot\left(p / p_{0}\right) \cdot m\right]}{\alpha \cdot \mu}$.

The term $F$ is directly derived from the Bentham measurements:

$F=\ln \frac{I_{\lambda}(\mathrm{A} 1)}{I_{\lambda}(\mathrm{A} 2)}-\ln \frac{I_{\lambda}(\mathrm{D} 1)}{I_{\lambda}(\mathrm{D} 2)}$.

The term $F_{0}$ is the extraterrestrial constant (ETC) for the instrument ( $F$ value outside the Earth's atmosphere):

$F_{0}=\ln \frac{I_{0 \lambda}(\mathrm{A} 1)}{I_{0 \lambda}(\mathrm{A} 2)}-\ln \frac{I_{0 \lambda}(\mathrm{D} 1)}{I_{0 \lambda}(\mathrm{D} 2)}$.

The ETC value is determined in this work from the extrapolation to zero air mass of each wavelength pair (Langley plot method), which is described in detail in the next section.

The term $\alpha$ is the differential absorption coefficient obtained as follows:

$\alpha=\left(\alpha_{\mathrm{A} 1}-\alpha_{\mathrm{A} 2}\right)-\left(\alpha_{\mathrm{D} 1}-\alpha_{\mathrm{D} 2}\right)$,

where $\alpha_{\mathrm{A} 1}, \alpha_{\mathrm{A} 2}, \alpha_{\mathrm{D} 1}, \alpha_{\mathrm{D} 2}$ are the Bass and Paur (1985) ozone absorption coefficients (the current remote sensing standard for ozone) at a fixed temperature of $227.0 \mathrm{~K}$ (Komhyr et al., 1993). This temperature must be representative of the average column temperature weighted by the ozone concentration (called effective temperature). The real effective temperature changes with the latitude and height of study site and season. Antón et al. (2008) showed that the effective temperature at Madrid for the period 1995-2002 ranges between $218 \mathrm{~K}$ (winter) and $232 \mathrm{~K}$ (summer) (see Fig. 6 therein), with a mean effective temperature of $226.5 \mathrm{~K}$. This value can be also assumed as representative for southern Spain. The literature shows that spectrophotometers (e.g., Brewer) yield near similar results when their operational retrieval is being performed with either the Bass and Paur or BDM (Brion, Daumont, Malicet) ozone absorption cross section data set (Redondas and Cede, 2006). These authors have also shown that with either cross section data set there is little to no dependence of the TOC estimate on the atmospheric temperature at which the ozone resides.
The terms $\beta$, related to the Rayleigh molecular scattering coefficients, is calculated as follows:

$\beta=\left(\beta_{\mathrm{A} 1}-\beta_{\mathrm{A} 2}\right)-\left(\beta_{\mathrm{D} 1}-\beta_{\mathrm{D} 2}\right)$,

where $\beta_{\mathrm{A} 1}, \beta_{\mathrm{A} 2}, \beta_{\mathrm{D} 1}, \beta_{\mathrm{D} 2}$ are derived from (Komhyr et al., 1989)

$\beta_{\lambda}=1.787 \cdot 10^{10}(\lambda)^{-4.25}$.

The atmospheric pressure needed to adjust the Rayleigh scattering coefficient was measured by an automatic weather station at the study site. Pressure data were recorded as $1 \mathrm{~min}$ averages and subsequently processed to hourly means.

The relative optical air mass of the whole atmosphere is obtained using the expression proposed by Kasten and Young (1989):

$m=\frac{1}{\left(\cos \theta+0.050572 \cdot(96.07995-\theta)^{-1.6364}\right)}$,

where $\theta$ is the SZA.

Finally, the optical air mass of the ozone layer, also called the ozone air mass factor (AMF), can be approximated to the following expression (Komhyr, 1980; Bernhard et al., 2005):

$\mu=\frac{1}{\sqrt{1-\frac{(R+r)^{2}}{(R+h)^{2}} \sin ^{2} \theta}}$,

where $R$ is the mean earth radius; $r$ is the height of the station above mean sea level, in kilometers; $h$ is the height of the ozone layer above mean sea level at station location; and $\theta$ is the SZA. We obtain this parameter by assuming a fixed value of 0.9965 for the ratio $(R+r) /(R+h)$, the same value used by the Brewer and Dobson algorithms (Basher et al., 1982). Using this fixed value together with a mean radius of the Earth of $6370 \mathrm{~km}$ and a null altitude for our ground-based station, the ratio assumes an ozone layer $21.99 \mathrm{~km}$ above the station. Antón et al. (2009) showed that the relative differences between the operational ozone AMF values considered by Brewer instruments and simulated values using real ozone profiles at Madrid are completely negligible for solar zenith angles smaller than $75^{\circ}$.

In the development of the above retrieval technique, it has been assumed that ozone is the most dominant absorption in the $305-340 \mathrm{~nm}$ spectral region, and so the effect of other UV absorbers is negligible. However, it is known that the accuracy of TOC measurements can be affected by the UV absorption from other atmospheric gases. In this sense, sulphur dioxide has been found to be the most relevant gas contributor to uncertainties in Dobson data at specific sites under particular atmospheric conditions. Thus, the errors in TOC data measured by the Dobson instruments are less than $1 \%$ in unpolluted locations, but they can reach up to $10 \%$ in areas with high local sulphur dioxide emissions during inversion situations (WMO, 2008b). 


\section{Extraterrestrial constant}

According to the Beer-Lambert law, the ratio between the direct-sun irradiance at two wavelengths $\lambda_{1}$ and $\lambda_{2}$ may be expressed as

$\ln \frac{I\left(\lambda_{1}\right)}{I\left(\lambda_{2}\right)}=\ln \frac{I_{0}\left(\lambda_{1}\right)}{I_{0}\left(\lambda_{2}\right)}-\left(\tau_{\lambda_{1}}+\tau_{\lambda_{2}}\right) \cdot m$,

where $\tau_{\lambda_{1}}$ and $\tau_{\lambda_{2}}$ are the total atmospheric optical depth for the wavelengths $\lambda_{1}$ and $\lambda_{2}$, taking into account all factors contributing to the solar attenuation.

If a series of direct-sun irradiance measurements is taken over a range of the relative optical air mass during which the total atmospheric optical depth remained constant, the term $\ln \frac{I_{0}\left(\lambda_{1}\right)}{I_{0}\left(\lambda_{2}\right)}$ may be determined from the ordinate intercept ( $m=0$, no atmosphere) of a least-squares fit between the term $\ln \frac{I\left(\lambda_{1}\right)}{I\left(\lambda_{2}\right)}$ and $m$. This procedure is a slight modification of the commonly known Langley plot technique (Thomason et al., 1982, 1983; Marenco et al., 2002), which utilizes spectral irradiance and not the ratios as in our method. To obtain the ETC (Eq. 4) of the Bentham instrument, this modified Langley method can be applied for the pairs of wavelengths A1-A2 and D1-D2.

We performed Langley plot analysis for 30 cloud-free half-days, originating from morning measurements in late spring and summer in 2005. Morning measurements have been chosen due to higher stability of atmospheric conditions during these periods as is explained in the next Section. The selection of cloud-free periods is based on the cloud cover information given by an all-sky imager (Cazorla et al., 2008, 2009). This camera provides images of the whole sky dome in daytime every $5 \mathrm{~min}$, being installed over the same sun tracker next to the Bentham collimator tube. The cloud cover is characterized in oktas (eighths of sky), taking exclusively those half-days with null oktas during the observation period which must cover air mass values smaller than 3 (SZA smaller than $70^{\circ}$ ). Additionally, the 30 selected cases satisfied the criterion that more than twenty direct irradiance spectra yielding a correlation in the Langley plots of better than 0.99 . However, this restrictive criterion may not guarantee that the data actually contain no optical depth variation. Thus, a slow and monotonic diurnal TOC variation may produce well-aligned data in the Langley plots, but their ordinate intercepts can differ substantially from the correct extraterrestrial constant (Arola and Koskela, 2004). In contrast, the ratio of the direct-sun irradiance at two very close wavelengths makes the Langley method employed in this work insensitive to changes in the atmospheric aerosol load (the aerosol optical thickness presents no significant dependence in the narrow spectral range employed for the TOC retrieval).

The Langley plots for the two pairs of wavelengths corresponding to a particular day (2 July 2005) are shown in Fig. 1. The two regression lines for the morning values have been added to the figure, their ordinate intercepts $(-0.41 \pm 0.01$ and $-0.36 \pm 0.01)$ being the two terms (left

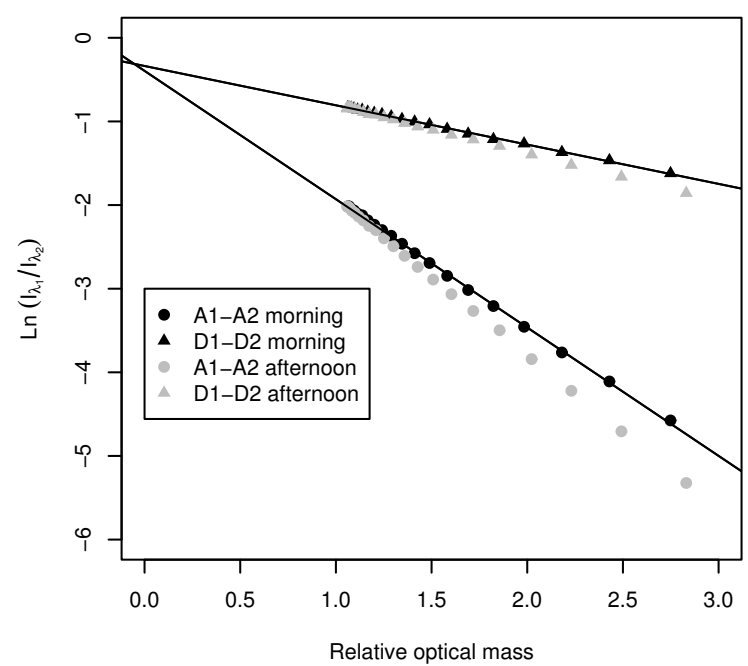

Fig. 1. Langley plots for the two pairs of wavelengths (A1-A2, D1D2) corresponding to 2 July 2005. Morning values (time $<12$ ) are shown in black, while afternoon values are displayed in grey. The two regression lines for the morning values have been added to the figure.

and right) of the Eq. (4) which allow the determination of the ETC $(-0.054 \pm 0.017)$. The error corresponds with the sum of the standard errors associated with the two ordinate intercepts. Additionally, the afternoon values for the two pairs of wavelengths have also been added to the plot. It can be seen that the data are well aligned, which could be confused with correct Langley plots. For these afternoon cases, the ordinate intercepts are $-0.109 \pm 0.005$ and $-0.27 \pm 0.004$, which lead to an erroneous ETC value of $+0.166 \pm 0.009$. This large difference between the morning and the afternoon ETC is related to the differential behavior of the TOC changes during these two periods, which is analyzed in the next section for this particular day.

Table 1 shows the main statistical parameters for the daily ETC obtained for the selected days. The ETC presents a coefficient of variation (SD/Mean) of $19 \%$, indicating a significant day-to-day variability of the calibration constant. This variability in the ETC values may be mainly associated with the diurnal TOC fluctuations commented above. It is well known that the correct application of the Langley method necessitates that the optical depth remains constant during the measured period. Nevertheless, Marenco (2002) showed that if a sufficiently large number of cloud-free half-days is available then a reliable ETC can be performed even at locations characterized by non-negligible short-term variability (disturbance) of atmospheric conditions. This author exhibited that these atmospheric variations act as random processes, so their influence on ETC may be minimized by averaging over a sufficiently large number of cloud-free half-days. In this sense, the average ETC value $(-0.071)$ obtained from the 30 daily values may be assumed as representative for the 
Table 1. Statistical parameters derived from the determination of the daily extraterrestrial constant of the Bentham spectroradiometer by the Langley technique for the 30 selected cloud-free half-days. The parameters are the following: the mean, the median, the standard deviation, percentiles 25 and 75, maximum and minimum.

\begin{tabular}{rrrrrrrr}
\hline & Mean & Median & Stand. Dev. & Perc. 25 & Perc. 75 & Max. & Min. \\
\hline ETC & -0.071 & -0.074 & 0.014 & -0.081 & -0.060 & -0.044 & -0.089 \\
\hline
\end{tabular}

real constant of the Bentham instrument, and, therefore, this mean value may be considered as the extraterrestrial constant in Eq. (2). The error of this mean ETC value is 0.019, which is derived from the average of the daily standard errors. Thus, the relative uncertainty of the ETC can be estimated around $27 \%$.

To analyze the effects of the large ETC uncertainty on TOC retrieved from the Bentham spectroradiometer, we have derived the experimental TOC data using the mean ETC $(-0.071)$, and the estimated TOC values using the following four ETC values: -0.044 (maximum), -0.060 (percentile 75), -0.081 (percentile 25) and -0.089 (minimum). The relative changes with respect to the mean ETC value are $38 \%, 15 \%, 14 \%$ and $25 \%$, respectively. The ratio of the estimated and the experimental TOC values is calculated for each Bentham spectrum recorded during the 30 selected half-days. Figure 2 shows all these ratios as a function of SZA. It can be seen that the influence of the ETC variability on TOC data is quite limited. Thus, the variations of the modeled TOC values with respect to the experimental data are smaller than $3 \%$, appreciating a decrease of the experimental-modeled TOC differences when the SZA increases (differences smaller than $1 \%$ for SZA of $70^{\circ}$ ). Therefore, the use of the mean ETC in Eq. (2) to obtain the Bentham TOC data introduces a reduced uncertainty in these experimental values.

\section{Results and discussion}

\subsection{Bentham total ozone data}

From each Bentham direct-sun spectrum, one TOC measurement was retrieved every 15 minutes between April 2005 and May 2006. Hourly TOC data were determined by the average of the four TOC measurements recorded every hour. The success of the TOC retrieval by the Bentham spectroradiometer is highly dependent on the stability of the atmosphere during the direct-sun measurements at each specific wavelength. In this sense, the variability of the cloud cover may produce strong changes on direct-sun measurements, making the TOC retrieval unreliable.

Figure 3 shows three plots with the diurnal evolution of the hourly TOC retrievals for several days. The error bars represent the standard deviation (SD) of the hourly averages. The three plots also include the diurnal evolution of the cloud cover, characterized in oktas from the all-sky imager

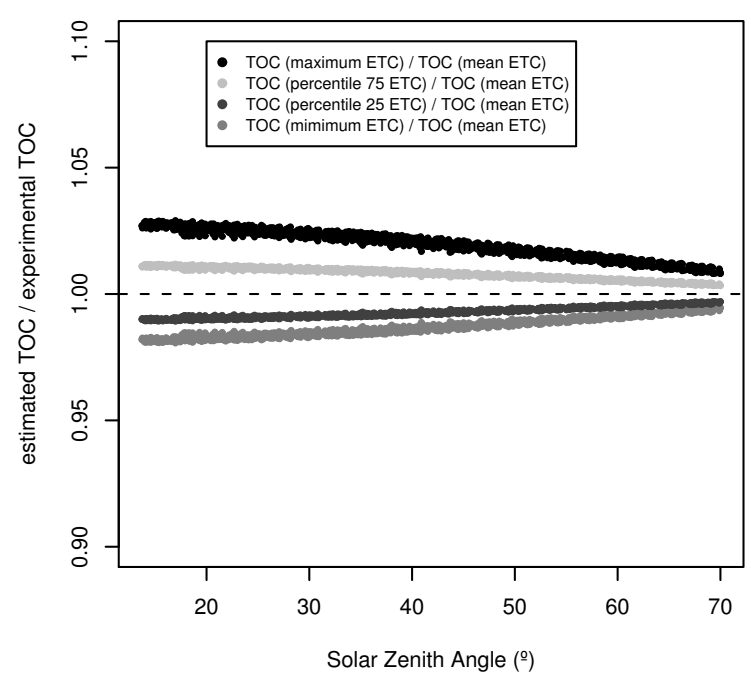

Fig. 2. The ratio of the estimated and the experimental total ozone column as a function of the solar zenith angle for the 30 selected cloud-free half-days (morning period). The experimental total ozone data have been derived using the mean ETC value, and the estimated data using the maximum, minimum, percentile 75 and percentile 25 ETC values.

described in the previous section. Additionally, the punctual daily TOC data given by the satellite OMI instrument over the study site have been added to the plots in order to have a reference value.

Figure 3 (top) shows the TOC evolution for the day 12 October 2005. It can be seen that the day presents cloud-free conditions (null oktas) until 14:00 GMT and then a substantial increase of the cloudiness with a maximum value of 7 oktas around 16:00 GMT. The Bentham TOC retrieval exhibits a great stability during the clear-sky period, with TOC values between 266 and 275 DU. The TOC value derived from the OMI instrument during the satellite overpass was $269 \mathrm{DU}$, indicating the good agreement between groundbased and satellite-based TOC measurements. In addition, for this clear-sky period, the SD presents values smaller than $3 \mathrm{DU}(\sim 1 \%)$ which point out the significance of the Bentham TOC data retrieved during cloud-free conditions. In contrast, the presence of clouds in the afternoon clearly makes the hourly TOC data unreliable, showing large error bars (SD higher than $28 \mathrm{DU}$ ) and a strong variability in the averages. Therefore, the SD parameter may be used for 

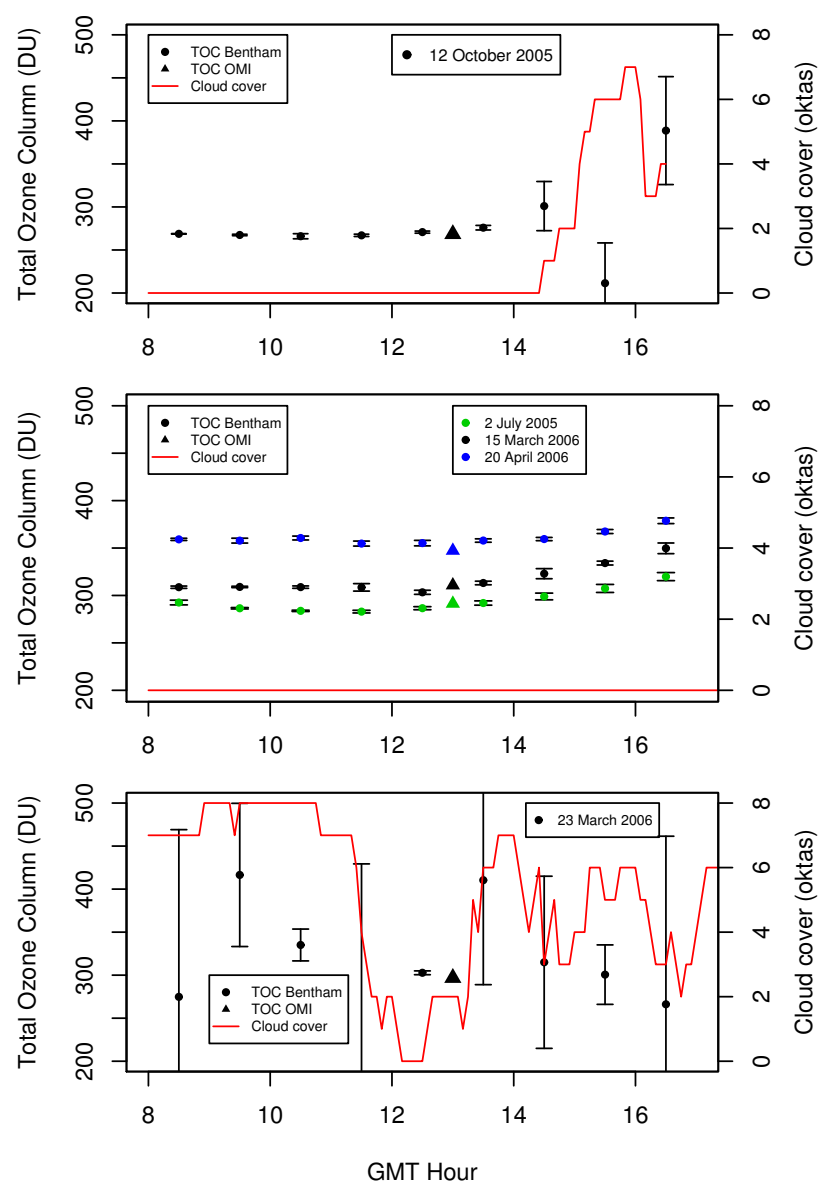

Fig. 3. Diurnal evolution of the total ozone column and the cloud cover characterized in oktas (eighths of sky) for the days 12 October 2005 (top), 2 July 2005, 15 March 2006 and 20 April 2006 (middle), and 23 March 2006 (bottom). The error bars represent the standard deviation (SD) of the hourly total ozone averages. The punctual daily total ozone data derived from the satellite Ozone Monitoring Instrument have been also included in the plots. DU, Dobson units.

selecting high-quality TOC data retrieved by the Bentham spectroradiometer.

The diurnal evolution of TOC retrievals for three completely cloud-free days (null oktas) is shown in Fig. 3 (middle). This plot exhibits the typical pattern of the diurnal variability of TOC data over Granada during spring-summer. Thus, it can be observed that TOC remains almost constant until midday, suffering then a monotonic increase toward sunset that can reach up to $40-50 \mathrm{DU}$ on certain days. Such strong short-term changes in total ozone may occur occasionally at mid- to high-latitude locations during late spring and summer (e.g., Tzortziou et al., 2012). For instance, on 2 July 2005 the TOC is nearly stable in the morning (time $<12 \mathrm{~h}$ ), with values in the range $280-293 \mathrm{DU}$ and a small coefficient of variation of $1.5 \%$. This first part of the TOC evolution corresponds to the two Langley extrapolations (black lines) shown in Fig. 1. A high TOC stability is found on most cloud-free mornings at Granada since, for example, the coefficient of variation is always lower than $2 \%$ for the 30 cloud-free mornings used to obtain the extraterrestrial constant. In the afternoon of 2 July 2005, the TOC shows a substantial linear increase from $292 \mathrm{DU}$ at 12:00 GMT to $336 \mathrm{DU}$ at 16:00 GMT, corresponding to the grey points in Fig. 1. This monotonic TOC variation is the cause which explains the large difference between the morning and afternoon ETC values pointed out in the previous section for this specific day.

The daytime pattern observed in Fig. 3 (middle) can be partially associated with the diurnal photochemical processes in the lower troposphere related to the formation of ozone near the Earth's surface at populated urban locations. It is known that the tropospheric ozone column represents about $10 \%$ of total column (between 30 and $40 \mathrm{DU}$ ), with up to $10 \mathrm{DU}$ in the boundary layer over major middle-latitude cities (Zbinden et al., 2006). Thus, surface ozone has a small contribution to total column but due to its marked daytime pattern (e.g., Ribas and Peñuelas, 2004; Adame et al., 2010) present a non-negligible effect on diurnal TOC variations. In this sense, Antón et al. (2010b) analyzed the simultaneous diurnal evolution of both surface and total column ozone data at Madrid. They showed diurnal TOC variations up to $20 \mathrm{DU}$ of which surface ozone changes could explain between $20 \%$ and $70 \%$, depending on the mixing layer height. The strong diurnal TOC variations (up to 40-50 DU) found on certain days at Granada cannot be exclusively explained by photochemical processes near the surface; therefore, other factors like transport processes in the upper troposphere and lower stratosphere could also present a significant contribution.

Finally, Fig. 3 (bottom) shows the TOC evolution for a cloudy day (23 March 2006) with a strong decrease of cloudiness around solar noon. Large error bars can be seen for most hourly Bentham averages, except the TOC value retrieved between 12:00 and 13:00 GMT with a value of $303 \pm 2 \mathrm{DU}$. This experimental data is very close to the satellite TOC value given by OMI (297 DU). For this one hour period, we observe that the cloud cover varies between 0 and 2 oktas. Therefore, partly cloudy conditions with the solar disk not obstructed by clouds throughout one hour can lead to obtaining low SD values and, thus, reliable hourly TOC data.

\subsection{Comparison against satellite observations}

To check the reliability of the TOC data retrieved by the Bentham spectroradiometer, we compare these ground-based data with independent high-quality observations inferred from three satellite instruments covering the ultraviolet spectral range: OMI, GOME and SCIAMACHY. The accuracy of these satellite TOC data is very high as they compare to wellestablished ground-truth reference data within a few percent (Fioletov et al., 2002; Bramstedt et al., 2003; Balis et al., 2007; Lerot et al., 2009; Antón et al., 2010, 2011a, b; Loyola et al., 2011). 
Table 2. Parameters obtained in the correlation analysis between satellite TOC data (OMI, GOME and SCIAMACHY) and Bentham measurements as gathered over Granada during the period between April 2005 and May 2006. The parameters are the following: the number of data $(N)$, the slope of the regression, the correlation coefficients $\left(R^{2}\right)$, the root mean square errors (RMSE), the mean bias $(\mathrm{MB})$ and the mean absolute bias (MAB).

\begin{tabular}{lrlrrrr}
\hline & $N$ & \multicolumn{1}{l}{ Slope } & $R^{2}$ & RMSE $(\%)$ & MB $(\%)$ & MAB (\%) \\
\hline OMI & 128 & $1.01 \pm 0.02$ & 0.93 & 2.38 & $-1.9 \pm 2.3$ & $2.5 \pm 1.7$ \\
GOME & 65 & $0.93 \pm 0.05$ & 0.86 & 3.14 & $+1.3 \pm 3.2$ & $2.7 \pm 2.1$ \\
SCIAMACHY & 75 & $0.96 \pm 0.05$ & 0.86 & 3.21 & $+0.6 \pm 3.2$ & $2.7 \pm 1.8$ \\
\hline
\end{tabular}

In this work, the satellite pixel most closely collocated with the ground-based station is selected as the best match every day. The satellite overpass is selected such that the distance between the center of the satellite pixel and the location of the ground-based stations is always less than 50, 100 and $200 \mathrm{~km}$ for OMI, SCIAMACHY and GOME, respectively. This large difference in the spatial collocation criteria is related to the different satellite footprint ground pixel size of the three instruments: $13 \times 24 \mathrm{~km}^{2}(\mathrm{OMI}), 60 \times 30 \mathrm{~km}^{2}$ (SCIAMACHY) and $320 \times 40 \mathrm{~km}^{2}$ (GOME). In addition, the OMI overpass time $(\sim 13: 30$ GMT $)$ differs with respect to overpass times for SCIAMACHY $(\sim 10: 30$ GMT) and GOME $(\sim 11: 00 \mathrm{GMT})$. In this sense, for comparison purposes, the Bentham TOC data derived each day between 13:00 and 14:00 GMT are averaged to be compared against punctual OMI data while the average Bentham data between 10:00 and 11:00 GMT are used to be compared against both SCIAMACHY and GOME data. Only those hourly TOC averages with a SD smaller than $10 \mathrm{DU}(\sim 3 \%)$ are assumed as valid and, therefore, utilized for intercomparison purposes. This restrictive threshold guarantees an unobstructed solar disk during the four direct solar spectrums measured within one hour.

A linear regression analysis is performed between the TOC values recorded by the Bentham spectroradiometer and the three satellite instruments in order to analyze their proportionality and similarity. Table 2 shows the number of pairs of ground-based and satellite-based data analyzed in this work, in addition to the slope of regression lines, coefficients of correlation $\left(R^{2}\right)$ and the root mean square errors (RMSE). It can be seen that the correlation between the satellite-based and ground-based TOC data is significantly high for the three satellite instruments, showing an excellent agreement $\left(R^{2} \sim 0.93\right.$ ) for OMI and a fairly good agreement $\left(R^{2} \sim 0.86\right)$ for GOME and SCIAMACHY (with a significantly small spread for the three correlations (RMSE lower than $3.2 \%)$ ). Moreover, the statistical analysis renders slopes very close to unity, indicative of their proportionality. Additionally, the three scatterplots shown in Fig. 4 reveal the high degree of agreement between satellite-based and groundbased TOC data. The solid line is the unit slope line with zero bias. The lower spread in the correlation for OMI than for GOME and SCIAMACHY could be partially related to the footprint ground pixel size being substantially smaller
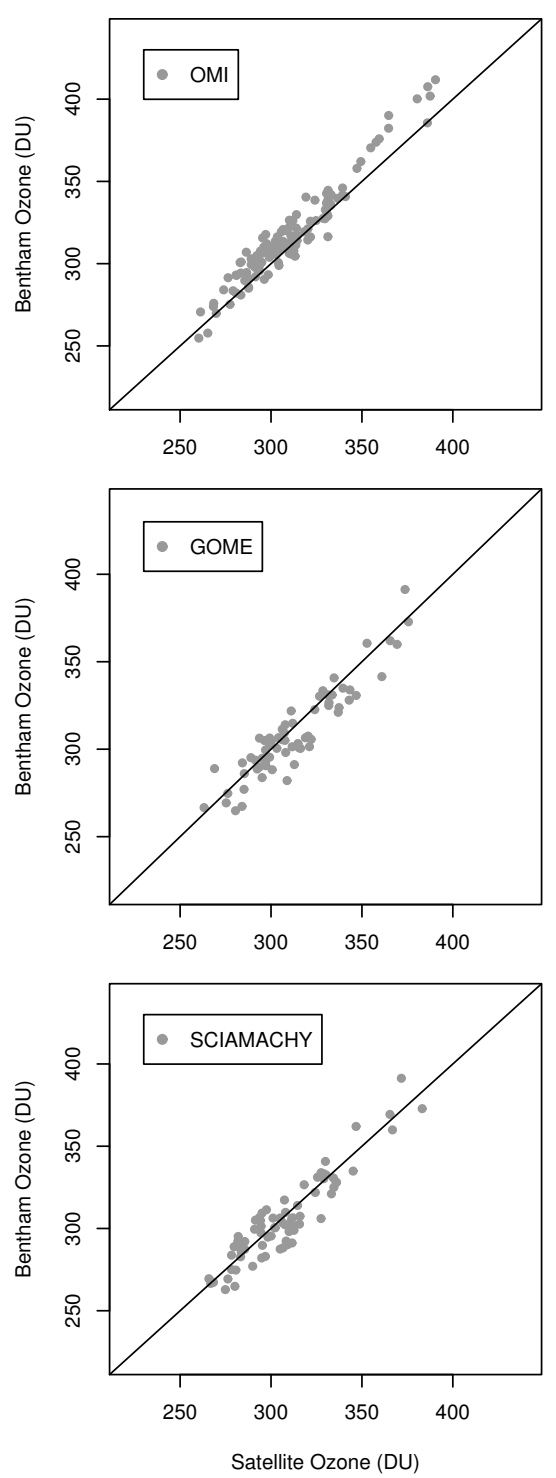

Fig. 4. Correlation between satellite and ground-based TOC data gathered over Granada for the period between April 2005 and May 2006. (top) OMI versus Bentham. (middle) GOME versus Bentham. (bottom) SCIAMACHY versus Bentham. The solid line represents the unit slope with which the data almost agree. DU, Dobson units. 
for OMI than for the other two satellite instruments as was pointed out in the previous paragraph. Although the spatial homogeneity of the stratospheric ozone layer (main contributor to the ozone column) is well known, the influence of surface ozone on ground-based-satellite comparisons at polluted urban locations like Granada could be non-negligible since the sensitivity of OMI, GOME and SCIAMACHY instruments to the ozone density is strongly height dependent in the troposphere (e.g., see Fig. 1 in Anton et al., 2011b).

Table 2 also shows the mean bias (MB) and the mean absolute bias $(\mathrm{MAB})$ parameters calculated from the relative differences between the daily Bentham (Ben) TOC data and the satellite TOC data (Sat) using the following expressions:

$\mathrm{MB}=\frac{1}{N} \sum_{i=1}^{N} \frac{\mathrm{Sat}_{i}-\mathrm{Ben}_{i}}{\mathrm{Ben}_{i}}$,

$\mathrm{MAB}=\frac{1}{N} \sum_{i=1}^{N}\left|\frac{\mathrm{Sat}_{i}-\mathrm{Ben}_{i}}{\mathrm{Ben}_{i}}\right|$,

where $N$ is the number of satellite-Bentham data pairs recorded at the study site.

The MB values close to zero indicate that there is no significant underestimation or overestimation of the TOC data retrieved from the Bentham instrument with respect to the satellite measurements. On average, the overestimation is only $0.6 \%$ with one standard deviation of $\pm 3.2 \%$ for SCIAMACHY and $(1.3 \pm 3.2) \%$ for GOME, while OMI slightly underestimates the Bentham data in $(1.9 \pm 2.3) \%$. A value of the standard deviation around $3 \%$ suggests that the random and systematic errors of TOC data inferred from both ground-based and satellite-based instruments are relatively small. In addition, MAB parameters are $2.5 \%$ (OMI), $2.7 \%$ (GOME) and $2.7 \%$ (SCIAMACHY) with standard deviations around $2 \%$, indicating the statistical significance of the reported values. All these results underline both the consistency and high reliability of the TOC measurements retrieved by the Bentham spectroradiometer located at Granada.

\section{Conclusions}

The method presented in this work to derive the total ozone column from direct-sun measurements is very promising and could be applied to any of the Bentham spectroradiometers available at many locations around the world.

The extraterrestrial constant of the Bentham instrument was obtained by the Langley extrapolation method. This technique is extremely sensitive to TOC fluctuations during the measurement period. Thus, a strong difference between the ETC derived from morning (nearly stable TOC values) and afternoon data (monotonic increase TOC values) during the same day can be observed at the study location. This behavior may be likely associated with the diurnal evolution of the surface ozone at populated urban locations. We chose 30 cloud-free half-days (morning period) to obtain the ETC of the Bentham spectroradiometer. The TOC presented a diurnal variability smaller than $2 \%$ for each one of the 30 selected half-days. These low fluctuations were enough to produce a large day-to-day ETC variability (coefficient of variation around $19 \%$ ). However, the influence of these changes on Bentham TOC retrieval was reduced. Thus, the use of an averaged ETC value as fixed calibration constant introduces a maximum uncertainty smaller than $3 \%$ in the TOC data.

A standard deviation of the hourly TOC values of $3 \%$ ( $\sim 10$ Dobson Unit) was assumed as the upper threshold to select high-quality Bentham data. This restrictive limit guarantees direct-sun measurements performed during cloud-free conditions or partly cloudy conditions without the solar disk obstructed.

The TOC data provided by the Bentham spectroradiometer were checked by comparisons with the satellite TOC data inferred from the OMI, GOME and SCIAMACHY instruments. The Bentham instrument showed a good agreement with the three satellite instruments, the mean absolute bias being lower than $3 \%$ and the standard deviations smaller than $2 \%$.

Overall the Bentham spectroradiometer has a high potential for the retrieval of reliable direct-sun TOC data, being a viable alternative to the widely utilized Brewer and Dobson spectrophotometers. We encourage other researchers with operative Bentham instruments to use them for retrieving TOC measurements by means of the differential absorption technique.

Acknowledgements. The authors would like to thank the teams responsible for the provision of satellite data used in this paper: the SCIAMACHY/ENVISAT products were provided by BIRA, the GOME/ERS-2 products were generated at DLR under the auspices of the D-PAF project funded by ESA, and the OMI/AURA products were provided by the OMI International Team. Authors also thank Prof. Ángel de Frutos from the University of Valladolid for the design of the collimator tube used to measure the direct-sun spectral measurements. Manuel Antón thanks Ministerio de Ciencia e Innovación and Fondo Social Europeo for the award of a postdoctoral grant (Ramón y Cajal). This work was partially supported by the Andalusian Regional Government through projects P08-RNM-3568 and P10-RNM-6299, the Ministerio de Ciencia e Innovación through projects CGL2008-05939-C03-02/CLI, CGL2008-05939-C03-03/CLI, CGL2010-18782, CGL-20112992-1-C02-01 and CSD2007-00067, and by the European Union through the ACTRIS project (EU INFRA-2010-1.1.16-262254).

Edited by: J. Joiner

\section{References}

Adame, J. A., Bolivar, J. P., and de la Morena, B.: Surface ozone measurements in the southwest of the Iberian Peninsula (Huelva, Spain), Environ Sci. Pollut. R., 17, 355-368, 2010. 
Antón, M., Loyola, D., Navascúes, B., and Valks, P.: Comparison of GOME total ozone data with ground data from the Spanish Brewer spectroradiometers, Ann. Geophys., 26, 401-412, doi:10.5194/angeo-26-401-2008, 2008.

Antón, M., López, M., Costa, M. J., Serrano, A., Bortoli, D., Bañón, M., Vilaplana, J. M., and Silva, A. M.: Influence of the ozone profile above Madrid (Spain) on Brewer estimation of ozone air mass factor, Ann. Geophys., 27, 3179-3183, doi:10.5194/angeo27-3179-2009, 2009.

Antón, M., Koukouli, M. E., Kroon, M., McPeters, R. D., Labow, G. J., Balis, D., and Serrano, A.: Global validation of empirically corrected EP-TOMS total ozone columns using Brewer and Dobson ground-based measurements, J. Geophys. Res., 115, D19305, doi:10.1029/2010JD014178, 2010a.

Antón, M., López, M., Serrano, A., Bañón, M., and García, J. A.: Diurnal variability of total ozone column over Madrid (Spain), Atmos. Environ., 44, 2793-2798, 2010 b.

Antón, M., Kroon, M., López, M., Vilaplana, J. M., Bañón, M., van der A, R., Veefkind, J. P., Stammes, P., and Alados-Arboledas, L.: Total ozone column derived from GOME and SCIAMACHY using KNMI retrieval algorithms: Validation against Brewer measurements at the Iberian Peninsula, J. Geophys. Res., 116, D22303, doi:10.1029/2011JD016436, 2011a.

Antón, M., Loyola, D., Clerbaux, C., López, M., Vilaplana, J. M., Bañón, M., Hadji-Lazaro, J., Valks, P., Hao, N., Zimmer, W., Coheur, P. F., Hurtmans, D., and Alados-Arboledas, L.: Validation of the MetOp-A total ozone data from GOME-2 and IASI using reference ground-based measurements at the Iberian Peninsula, Remote Sens. Environ., 115, 1380-1386, 2011b.

Arola, A. and Koskela, T.: On the sources of bias in aerosol optical depth retrieval in the UV range, J. Geophys. Res., 109, D08209, doi:10.1029/2003JD004375, 2004.

Balis, D., Kroon, M., Koukouli, M. E., Brinksma, E. J., Labow, G., Veefkind, J. P., and McPeters, R. D.: Validation of Ozone Monitoring Instrument total ozone column measurements using Brewer and Dobson spectrophotometer ground-based observations, J. Geophys. Res., 112, D24S46, doi:10.1029/2007JD008796, 2007.

Basher, R. E.: Review of the Dobson Spectrophotometer and its accuracy, Global Ozone Res. Monit. Proj. Rep. 13, World Meteorol. Org., Geneva, Switzerland, 1982.

Bass, A. M. and Paur, R. J.: The ultraviolet cross-sections of ozone, in Atmospheric Ozone: Proceedings of the Quadrennial Ozone Symposium, edited by: Zerefos, C. S. and Ghazi, A., 606-616, 1985.

Bernhard, G. and Seckmeyer, G.: Uncertainty of measurements of spectral solar UV irradiance, J. Geophys. Res., 104, 1432114346, 1999.

Bernhard, G., Evans, R. D., Labow, G. J., and Oltmans, S. J.: Bias in Dobson total ozone measurements at high latitudes due to approximations in calculations of ozone absorption coefficients and air mass, J. Geophys. Res., 110, D10305, doi:10.1029/2004JD005559, 2005.

Bhartia, P. K. and Wellemeyer, C.: TOMS-V8 total O3 algorithm, in: OMI Algorithm Theoretical Basis Document, Vol. II, OMI Ozone Products, edited by: Bhartia, P. K., 15-31, NASA Goddard Space Flight Cent., Greenbelt, Md., 2002.

Bojkov, R. D., Fioletov, V. E., and Shalamjansky, A. M.: Total ozone changes over Eurasia since 1973 based on reevaluated fil- ter ozonometer data, J. Geophys. Res., 99, 22985-22999, 1994.

Bovensmann, H., Burrows, J. P., Buchwitz, M., Frerick, J., Noël, S., Rozanov, V. V., Chance, K. V., and Goede, A. P. H.: SCIAMACHY: Mission objectives and measurement modes, J. Atmos. Sci., 56, 127-150, 1999.

Bramstedt, K., Gleason, J., Loyola, D., Thomas, W., Bracher, A., Weber, M., and Burrows, J. P.: Comparison of total ozone from the satellite instruments GOME and TOMS with measurements from the Dobson network 1996-2000, Atmos. Chem. Phys., 3, 1409-1419, doi:10.5194/acp-3-1409-2003, 2003.

Brogniez, C., Houet, M., Siani, A. M., Weihs, P., Allaart, M., Lenoble, J., Cabot, T., de la Casiniere, A., and Kyro, E.: Ozone column retrieval from solar UV measurements at ground level: Effects of clouds and results from six European sites, J. Geophys. Res., 110, D24202, doi:10.1029/2005JD005992, 2005.

Burrows, J. P., Weber, M., Buchwitz, M., Razonov, V., Ladstatter, A., Richter, A., De Beerk, R., Hoogen, R., Bramsdted, D., Eichmann, K. U., Eisenger, M., and Perner, D.: The Global Ozone Monitoring Experiment (GOME): mission concept and first scientific results, J. Atmos. Sci., 56, 151-175, 1999.

Cazorla, A., Olmo, F. J., and Alados-Arboledas, L.: Development of a sky imager for cloud cover assessment, J. Opt. Soc. Am. A., 25, 29-39, doi:10.1364/JOSAA.25.000029, 2008.

Cazorla, A., Shields, J. E., Karr, M. E., Olmo, F. J., Burden, A., and Alados-Arboledas, L.: Technical Note: Determination of aerosol optical properties by a calibrated sky imager, Atmos. Chem. Phys., 9, 6417-6427, doi:10.5194/acp-9-6417-2009, 2009.

Fioletov, V. E., Kerr, J. B., Wardle, D. I., Krotkov, N., and Herman, J. R.: Comparison of Brewer ultraviolet irradiance measurements with total ozone mapping spectrometer satellite retrievals, Opt. Eng., 41, 3051-3061, doi:10.1117/1.1516818, 2002.

Flynn, L. E., Labow, G. L., Beach, R. A., and Rawlins, M. A.: Estimation of ozone with total ozone portable spectroradiometer instruments, I, Theoretical model and error analysis, Appl. Optics, 35, 6076-6083, 1996.

Gao, W., Slusser, J., Gibson, J., Scott, G., Bigelow, D., Kerr, J., and McArthur, B.: Direct-Sun column ozone retrieval by the ultraviolet multifilter rotating shadow-band radiometer and comparison with those from Brewer and Dobson spectrophotometers, Appl. Optics, 40, 3149-3155, 2001.

Iqbal, M.: An Introduction to Solar Radiation, Academic, Canada, 1983.

Kasten, F. and Young, A.T.: Revised optical air mass tables and approximation formula, Appl. Optics, 28, 4735-4738, 1989.

Kerr, J. B., McElroy, C., and Evans, V.: The automated Brewer spectrophotometer,in Proceedings of the Quadrennial Ozone Symposium, edited by: Zerefos, C. S. and Ghazi, A., 396-401, Am. Meteorol. Soc., Boston, Mass, 1984.

Kiedron, P., Beauharnois, M., Berndt, J., Disterhoft, P., Harrison, L., Michalsky, J., Scott, G., Schlemmer, J., and Slusser, J.: Calibration, data processing, and maintenance of the United States Department of Agriculture high-resolution ultraviolet spectroradiometers, Opt. Eng., 46, doi:10.1117/1.2769599, 2007.

Kiehl, J. T., Schneider, T. L., Portmann, R. W., and Solomon, S.: Climate forcing due to tropospheric and stratospheric ozone, J. Geophys. Res., 104, 31239-31254, 1999.

Komhyr, W. D.: Operations handbook-ozone observations with a Dobson spectrophotometer, WMO Global Ozone Research and Monitoring, Project Rep. 6, World Meteorological Organization, 
Geneva, Switzerland, 1980.

Komhyr, W. D., Grass, R. D., and Leonard, R. K.: Dobson spectrophotometer 83: a standard for total ozone measurements, 1962-1987, J. Geophys. Res., 94, 9847-9861, 1989.

Komhyr, W. D., Mateer, C. L., and Hudson, R. D.: Effective BassPaur 1985 ozone absorption-coefficients for use with Dobson Ozone Spectrophotometers, J. Geophys. Res., 98, 20451-20465, 1993.

Lenoble, J., de La Casiniére, A., and Cabot, T.: Analysis of direct solar ultraviolet irradiance measurements in the French Alps. Retrieval of turbidity and ozone column amount, Appl. Optics, 43, 3133-3139, 2004.

Lenoble, J., Brogniez, C., de La Casinière, A., Cabot, T., Buchard, V., and Guirado, F.: Measurements of UV aerosol optical depth in the French Southern Alps, Atmos. Chem. Phys., 8, 6597-6602, doi:10.5194/acp-8-6597-2008, 2008.

Lerot, C., Van Roozendael, M., van Geffen, J., van Gent, J., Fayt, C., Spurr, R., Lichtenberg, G., and von Bargen, A.: Six years of total ozone column measurements from SCIAMACHY nadir observations, Atmos. Meas. Tech., 2, 87-98, doi:10.5194/amt-287-2009, 2009.

Levelt, P. F., Hilsenrath, E., Leppelmeier, G. W., Van den Oord, G. H. J., Bhartia, P. K., Tamminen, J., De Haan, J. F., and Veefkind, J. P.: The Ozone Monitoring Instrument, IEEE T. Geosci. Remote Sens., 44, 1093-1101, doi:10.1109/TGRS.2006.872333, 2006.

Long, C. S., Miller, J. A., Lee, H. T., Wild, J. D., Przywarty, R. C., and Huffor, D.: Ultraviolet Index forecasts issued by the NationalWeather Service, B. Am. Meteorol. Soc., 77, 729-748, 1996.

Loyola, D., Valks, P., Zimmer, W., Hao, N., Van Roozendael, M., Spurr, R. J. D., Lerot, C., Lambert, J.-C., Koukouli, M. E., and Balis, D. S.: The GOME-2 total column ozone product: retrieval algorithm and ground-based validation, J. Geophys. Res., 116, D07302, doi:10.1029/2010JD014675, 2011.

Marenco, F., di Sarra, A., and De Luisi, J.: Methodology for determining aerosol optical depth from Brewer 300-320-nm ozone measurements, App. Optics, 41, 1805-1814, 2002.

Morys, M., Mims, F. M., Hagerup, S., Anderson, S. E., Baker, A., and Walkup, T.: Design, calibration, and performance of MICROTOPS II handheld ozone monitor and Sun photometer, J. Geophys. Res., 106, 14573-14582, 2001.

Redondas, A. and Cede, A.: Brewer algorithm sensitivity analysis, paper presented at SAUNA Workshop, Span. Meteorol. Agency, Puerto de la Cruz, Spain, 2006.

Rex, M., von der Salawitch, R. J. P., Gathen, N. R., Harris, P., Chipperfield, M., and Naujokat, B.: Arctic ozone loss and climate change, Geophys. Res. Lett., 31, L04116, doi:10.1029/2003GL018844, 2004.

Ribas, P. and Peñuelas, J.: Temporal patterns of surface ozone levels in different habitats of the North Western Mediterranean basin, Atmos. Environ., 38, 985-992, 2004.

Román, R., Antón, M., Valenzuela, A., Gil, J. E., Lyamani, H., de Miguel, A., Olmo, F. J., Bilbao, J., and Alados-Arboledas, L.: Evaluation of the desert dust effects on global, direct and diffuse spectral ultraviolet irradiance, Tellus B, 65, 19578, doi:10.3402/tellusb.v65i0.19578, 2013.

Scarnato, B., Staehelin, J., Peter, T., Gröbner, J., and Stübi, R.: Temperature and slant path effects in Dobson and Brewer total ozone measurements, J. Geophys. Res., 114, D24303, doi:10.1029/2009JD012349, 2009.
Schmalwieser, A. W. and Schauberger, G.: Validation of the Austrian forecast model for solar, biologically-effective ultraviolet radiation-UV index for Vienna, Austria, J. Geophys. Res., 105, 26661-26668, 2000.

Slaper, H., Reinen, H., Blumthaler, M., Huber, M., and Kuik, F.: Comparing ground-level spectrally resolved solar UV measurements using various instruments: a technique resolving effects of wavelength shift and slit width, Geophys. Res. Lett., 22, 27212724, 1995.

Sperling, A., Winter, S., Raatz, K.-H., and Metzdorf, J.: Entwicklung von Normallampen für das UV-B_Messprogramm, PTBBer. PTB-Opt-52, Braunschweig, Germany, 1996.

Thomason, L. W., Herman, B. M., Schotland, R. M., and Reagan, J. A.: Extraterrestrial solar flux measurements limitations due to a Beer's law assumption and uncertainty in local time, Appl. Optics, 21, 1191-1195, 1982.

Thomason, L. W., Herman, B. M., and Reagan, J. A.: The effect of atmospheric attenuators with structured vertical distributions on air mass determinations and Langley plot analyses, J. Atmos. Sci., 40, 1851-1854, 1983.

Tzortziou, M., Herman, J. R., Cede, A., and Abuhassan, N.: High precision, absolute total column ozone measurements from the Pandora spectrometer system: Comparisons with data from a Brewer double monochromator and Aura OMI, J. Geophys., Res., 117, D16303, doi:10.1029/2012JD017814, 2012.

Vanicek, K.: Differences between ground Dobson, Brewer and satellite TOMS-8, GOME-WFDOAS total ozone observations at Hradec Kralove, Czech, Atmos. Chem. Phys., 6, 5163-5171, doi:10.5194/acp-6-5163-2006, 2006.

Van Roozendael, M., Loyola, D., Spurr, R., Balis, D., Lambert, J. C., Livschitz, Y., Valks, P., Ruppert, T., Kenter, P., Fayt, C., and Zehner, C.: Ten years of GOME/ERS-2 total ozone data - The new GOME data processor (GDP) version 4: 1. Algorithm description, J. Geophys. Res., 111, D14311, doi:10.1029/2005JD006375, 2006.

World Meteorological Organization (WMO): Comparison of total ozone measurements of Dobson and Brewer spectrophotometers and recommended transfer function, Global Ozone Res. Monit. Proj. Rep. 149, Geneva, Switzerland, 2003.

World Meteorological Organization (WMO): Global ozone research and monitoring project, Tech. Rep. 50, Sci. Assess. of Ozone Depletion, Geneva, Switzerland, 2006.

World Meteorological Organization (WMO): Operations Handbook - Ozone observations with a Dobson Spectrophotometer, Revised 2008, GAW Report No. 183, WMO/TD No. 1469, Geneva, Switzerland, 2008a.

World Meteorological Organization (WMO): Guide to meteorological instruments and methods of observation, 7th Edn. WMO Publication \#8, Geneva, Switzerland, 2008b.

Zbinden, R. M., Cammas, J.-P., Thouret, V., Nédélec, P., Karcher, F., and Simon, P.: Mid-latitude tropospheric ozone columns from the MOZAIC program: climatology and interannual variability, Atmos. Chem. Phys., 6, 1053-1073, doi:10.5194/acp-6-1053-2006, 2006.

Zerefos, C. S., Tourpali, K., Eleftheratos, K., Kazadzis, S., Meleti, C., Feister, U., Koskela, T., and Heikkilä, A.: Evidence of a possible turning point in solar UV-B over Canada, Europe and Japan, Atmos. Chem. Phys., 12, 2469-2477, doi:10.5194/acp-12-24692012, 2012. 